\title{
SAÚDE INFANTIL
}

A escolha desse tema para o editorial justifica-se pela sua relevância social e quantidade de artigos, na área de saúde da criança e do adolescente, publicados neste volume da Revista Latino-Americana de Enfermagem.

Nas últimas décadas, houve mudanças importantes no cenário demográfico nacional destacando-se o acelerado processo de urbanização, o declínio das taxas de fecundidade e de natalidade e o progressivo envelhecimento da população. Apesar da transição demográfica, o Brasil ainda é um dos países de estrutura etária jovem, quando comparado com outros países.

O perfil de mortalidade da população brasileira também alterou-se consideravelmente, seguindo a tendência internacional. De 1990 a 1995, a mortalidade infantil (<1 ano) caiu em cerca de $20 \%$ e na infância (até 5 anos) em 23\%; no ano de 1996 essas taxas eram de 44 e 52 por mil nascidos vivos, respectivamente. O Ministério da Saúde estima para o ano 2000 a mortalidade infantil em 23 por mil nascidos vivos.

A redução da mortalidade infantil deveu-se principalmente ao componente pós-natal enquanto que o neonatal tornou-se maior em termos proporcionais, embora também tenha decrescido, tendo as afeções perinatais como uma das principais causas de óbitos. $\mathrm{O}$ declínio observado deveu-se à menor incidência de desnutrição infantil, redução dos óbitos por gastroenterites, infecções respiratórias agudas e por doenças preveníveis por vacinação.

Dentre os fatores explicativos deste descenso da mortalidade infantil destacam-se as medidas de controle das doenças endêmicas, medidas sanitárias e preventivas, vigilância epidemiológica das enfermidades imunopreveníveis, disseminação dos serviços de saúde e saneamento básico.

Na infância, as principais causas de óbitos são as enfermidades transmissíveis, causas externas e tumores. Entre os escolares e adolescentes destacam-se as causas externas e doenças crônico-degenerativas; cabe assinalar as complicações da gravidez, parto e puerpério como importante causa de óbito entre as adolescentes.

A incorporação de tecnologias de alta complexidade no processo de diagnóstico e terapêutica também tem contribuído para a maior sobrevida das crianças, especialmente entre aquelas nascidas prematuras e portadoras de enfermidades crônico-degenerativas. Todavia, o impacto dessas medidas na qualidade de vida das crianças não tem ocorrido na mesma dimensão, repercutindo no perfil de morbidade.

Com as transformações no cenário epidemiológico e na assistência à saúde da criança e do adolescente, os profissionais de saúde têm se deparado com uma clientela crescente de portadores de enfermidades crônicas que necessitam de um seguimento especializado e acompanhamento a longo prazo.

Neste contexto, novas necessidades se colocam no trabalho em saúde e a enfermagem tem incorporado novos instrumentos de trabalho no processo de assistência à saúde da criança e do adolescente. As intervenções ampliaram-se para além da recuperação do corpo doente e a família, em especial os pais, constitue elemento essencial na assistência, visando a promoção da saúde e a prevenção de danos. A permanência dos pais ou responsável, em tempo integral, durante a internação da criança ou adolescente, tornou-se um direito assegurado no Estatuto, Lei n$^{\circ} 8.069$, de 13 de julho de 1990.

A enfermagem, através das práticas assistenciais e da produção de conhecimento científico, tem trazido

* Professora Doutora do Departamento de Enfermagem Materno-Infantil e Saúde Pública da Escola de Enfermagem de Ribeirão Preto da Universidade de São Paulo 
as suas contribuições para o processo de construção de uma assistência integral e humanizada na área de saúde da criança e do adolescente.

\section{FONTES:}

A CRIANÇA BRASILEIRA: um panorama da infância no país. Problemas Brasileiros. http://www.uol.com.br/ $\mathrm{sesc} / \mathrm{spu} / \mathrm{spupb} / \mathrm{htm}, 4 / 9 / 97$.

OPS. Las condiciones de salud en las Americas. Washington DC, OPS, 1994. 2v.

UNICEF. http://www.unicef.org.br/htm, 10/3/98. 